\title{
Sex Dimorphisms in the Rate of Age-Related Decline in Spatial Memory: Relevance to Alterations in the Estrous Cycle
}

\author{
Alicja L. Markowska \\ Neuromnemonics Laboratory, Department of Psychology, The Johns Hopkins University, Baltimore, Maryland 21218
}

The present experiments demonstrate the existence of sex differences in the rate of development and the magnitude of age-dependent impairments in cognitive and sensorimotor abilities. Although no sex differences were found in spatial reference memory at a young age, the mnemonic ability of female rats deteriorated more rapidly than that of male rats. A major drop in reference memory of the females occurred at the age of 12 months, whereas in the males the onset of impairments occurred later, at the age of 18 months. In spatial working memory, on the other hand, the magnitude of decline was greater in females than in males, although the onset of these impairments occurred at the age of 24 months in both sexes. A sexual dimorphism-aging interaction also was observed in sen- sorimotor performance. Up to the age of 18 months the females outperformed the males. Subsequently, by the age of 24 months, the performance of the females declined to a level similar to that of the males. The deficits observed in reference and working memory seem to be cognitive in origin and not attributable to alterations in sensory and motor abilities. In addition, the earlier onset of reference memory impairments in females generally coincides with the onset of alterations in the estrous cycle, suggesting that a decline in the estrogenic milieu of the females could be a factor in accelerating the rate of age-related cognitive impairments in the female rat.

Key words: sex dimorphism; spatial memory; estrous cycle; aging; Fischer-344 rats; estrogen
Sex differences in the performance of spatial tasks in humans, although small, are among the more reliably documented differences in cognitive ability. Several studies indicate that women outperform men in verbal and memory tasks, whereas men excel in tasks that require spatial ability, including simple perception or spatial rotation tests (Jarvik, 1975; Linn and Petersen, 1985; Halpern, 1986; Kimura and Hampson, 1994; Delgado and Prieto, 1996; Collins and Kimura, 1997). Similarly, among rodents, males tend to perform better than females in a variety of spatial tasks (Krasnoff and Weston, 1976; Beatty, 1979; Williams et al., 1990; Williams and Meck, 1991; Roof, 1993; Maren et al., 1994; Markus and Zecevic, 1997). Some of these differences can be attributed to variations in other behavioral processes, such as the greater locomotor activity of the females (Archer, 1979; Beatty, 1979; Gaulin et al., 1990), which, in turn, could account for the greater incidence of error for the females in a maze situation. In addition, sex differences have not been documented consistently or reported to be very modest in the performance of the radial maze task (Juraska et al., 1984; van Haaren et al., 1987; Luine and Rodriguez, 1994), a task assessing spatial working memory, which depends primarily on choice accuracy rather than on the level of activity (Olton and Papas, 1979). However, superiority of the males over the females was observed more reliably in a version of the radial maze task in which the memory demands were increased and response strategies were discouraged (Mishima et al., 1986; Williams et al., 1990; Williams and Meck, 1991). Similarly, numerous studies have used the Morris water maze to assess

Received Nov. 18, 1998; revised June 21, 1999; accepted July 2, 1999.

This study was supported by National Institute on Aging Grants AG07735 and AG15947. I thank Dr. A. Savonenko for excellent statistical consulting and M. Barra, D. Grinnell, M. Mooney, and T. Stiefel for their assistance with behavioral testing and data analyses.

Correspondence should be addressed to Dr. Alicja L. Markowska, Department of Psychology, Johns Hopkins University, Baltimore, MD 21218.

Copyright (C) 1999 Society for Neuroscience $0270-6474 / 99 / 198122-12 \$ 05.00 / 0$ spatial memory and have found that, at a young age, males outperformed females (Roof, 1993). However, other studies also conducted on young rats did not confirm these observations, suggesting instead the absence of sex differences in the water maze performance (Roof, 1993; Berger-Sweeney et al., 1995; Bucci et al., 1995; Warren and Juraska, 1997).

Aging also influences spatial memory (Crook et al., 1986; Zola-Morgan et al., 1986; Rapp et al., 1997). Although agerelated deficits in spatial memory have been observed in both male (Gallagher and Pelleymounter, 1988; Davis et al., 1993; Markowska et al., 1994, 1996; Frick et al., 1995) and female rats (Fischer et al., 1991), none of the studies has compared directly the effects of aging on the two genders in rats. The evidence of a sexual dimorphism in spatial memory at young ages (Williams et al., 1990; Roof, 1993; Maren et al., 1994; Markus and Zecevic, 1997) raises the question of whether the process of aging interacts with gender in the development of a decline in spatial memory.

It is well established that estrogens affect the brain throughout the life span. Moreover, the effects of those hormones are not limited to the areas primarily involved in reproduction but also include areas relevant to memory, such as the basal forebrain, the hippocampus, and the cortex (for review, see Luine, 1997; McEwen et al., 1997). Many of these same regions influenced by gonadal hormones also are affected strongly by aging (Geinisman et al., 1986) and are the sites of extensive neural degeneration in dementing illnesses, such as Alzheimer's disease (Terry and Katzman, 1983; Perry, 1986; Price and Sisodia, 1994). Substantial alterations in the hormonal milieu occur with aging and particularly at the time of menopause, which could alter the effects of aging on cognitive performance. Some aspects of this memory decline are prevented or reversed with estrogen supplementation (Sherwin, 1994, 1997, 1998a,b; Kampen and Sherwin, 1996; Sherwin and Tulandi, 1996; Espeland et al., 1998). This in turn strongly suggests a link between estrogen deficiency and memory 
impairment with age. Further, there is extensive evidence that estrogen levels are correlated positively with dendritic spine densities and synapse numbers within the CA1 region of the hippocampus (Gould et al., 1990; Woolley et al., 1990; Woolley and McEwen, 1993) and that estrogen administration ameliorates learning deficits and cholinergic abnormalities in ovariectomized rats (Simpkins et al., 1994; Singh et al., 1994; Grinnell and Markowska, 1998).

In addition, ovarian hormones interact with neurotrophic mechanisms (Gibbs and Pfaff, 1992; Garcia-Segura et al., 1994; Gibbs et al., 1994; Simpkins et al., 1994; Gibbs, 1996; ToranAllerand, 1996) and upregulate hippocampal NMDA receptor protein levels (Gazzaley et al., 1996). Taken together, these lines of evidence indicate that there is a variety of mechanisms by which alterations of the cyclic hormones production during estropause might compromise memory capacities of the aged brain. On the basis of these considerations, we hypothesize that the dynamics of age-related changes in spatial memory may have a different time course in male and female rats and that the onset of the cognitive impairments in female rats may reflect additive or interactive deficits from both aging and the alterations in the estrogen milieu.

\section{MATERIALS AND METHODS}

\section{Subjects}

Sixty-two Fischer-344 male (m) and 49 female (f) rats were acquired from the colony at the National Center for Toxicology Research (Jefferson, AK). They were of multiple ages-6, 12, 18, and 24 months-chosen to determine patterns of behavioral changes (Coleman et al., 1990) in males and females throughout life. The rats were housed on a $12 \mathrm{hr}$ light/dark cycle, three to four rats per cage to stimulate social interactions (Wade and Maier, 1986), and were matched by sex and age. The number of animals in each group is indicated in parentheses: 6-monthold m (10), 6-month-old f (12), 12-month-old m (20), 12-month-old f (12), 18-month-old $\mathrm{m}$ (10), 18-month-old f (11), 24-month-old $\mathrm{m}$ (22), and 24-month-old f (14). Food and water were provided ad libitum. Animals with obvious health problems (e.g., cataracts, glaucoma, or debilitating tumors) were eliminated from the study.

\section{Experimental design}

Each rat was handled for 5-10 min per day over the $5 \mathrm{~d}$ before the behavioral testing. After handling, the rats were tested in the following order: straight swim (SS) in the water maze (2 sessions/1 d), place discrimination (PD) in the water maze (4 sessions $/ 2 \mathrm{~d})$, sensorimotor tasks (SM; 1 session/1 d), repeated acquisition (RA) in the water maze ( 4 sessions $/ 2 \mathrm{~d}$ ), and cued learning in the water maze ( 1 session $/ 1 \mathrm{~d})$. The procedures conducted for two sessions a day used an inter-session interval of $2 \mathrm{hr}$. All behavioral testing was conducted in six batches of $\sim 20$ animals each. To control for neuroendocrine status, we obtained daily smears to determine the regularity of the estrous cycle in the female rats. The body weight was recorded twice weekly.

\section{Water maze procedures}

Apparatus. The water tank has been described in detail previously (Markowska et al., 1993). Briefly, the tank was $1.8 \mathrm{~m}$ in diameter. The collapsible escape platform (Lucite, $10 \times 10 \mathrm{~cm}$ ) was $1 \mathrm{~cm}$ below the surface of the water and accessible to the rat. In its lowered position the platform was unavailable at $19 \mathrm{~cm}$ beneath the surface of the water. Performance in the water maze was recorded by an automated tracking system (HVS Image Analysis V P-112, HVS Image, Hampton, England), which acquired images through a camera (Burle Security Products, Lancaster, PA) mounted $1.4 \mathrm{~m}$ above the surface of the water. Two identical water maze tanks located in different rooms with different spatial cues were used for place discrimination and repeated acquisition procedures. The straight swim and cue tasks were conducted in the tank used for place discrimination. However, for those procedures the tank was surrounded by black curtains to prevent the rats from using spatial cues.

Straight swim (SS). This test, described in detail previously
(Markowska et al., 1993), assessed the swimming ability of the rat and trained the rat to swim down to and climb onto the platform at the end of a narrow alley. Without this previous shaping, swim performance could influence the first few trials of acquisition in the discrimination tasks. Before the first trial the rat initially was placed on the escape platform for $10 \mathrm{sec}$. For the trial itself the rat was placed in the alley and allowed to swim to the platform. Two sessions consisting of five trials each were conducted for each rat. Swim Time, the time needed to reach the platform, was recorded.

Place discrimination $(P D)$. Place discrimination assessed the rat's ability to identify the location of the hidden platform (constant across all sessions) from several different starting locations. The variable interval (VI) probe trial (Markowska et al., 1993) was used to provide measures of spatial memory different from those obtained from the platform trial.

For each platform trial, the platform was placed in the same location across all trials at $1 \mathrm{~cm}$ below the surface of the water. The start locations varied across the trials. If the rat had not reached the platform within 1 min after the start of the trial, the experimenter guided the rat to the platform. After reaching the platform, the rat was allowed to remain on it for $10 \mathrm{sec}$ and then was returned to the holding cage for an inter-trial interval (ITI) of $\sim 3 \mathrm{~min}$.

For each VI probe trial, all procedures were identical to those of the platform trials, with two exceptions. (1) At the beginning of the trial the platform was in its lowered position so that it was unavailable to the rat. (2) At some variable interval from the start of the trial $(10,40,20$, or 30 sec) the platform was raised so that it was available to the rat.

Before the first platform trial the rat was placed on the platform for 10 sec. Each session consisted of five platform trials, followed by one probe trial. For $2 \mathrm{~d}$ two sessions were given each day, with an inter-session interval (ISI) of $2 \mathrm{hr}$ (a total of four sessions).

For the platform trials' measures of performance (Swim Time, Swim Distance, and Heading Angle), lower scores indicated a better performance. For the VI probe trials' measures of performance [Target Quadrant (percentage of time spent in the quadrant containing the platform), Annulus-40 (percentage of time spent in a circle with a diameter of $40 \mathrm{~cm}$ centered on the location of the platform), and Platform Crossings (number of times the rat crossed over the platform location)], higher scores indicated a better performance.

Repeated acquisition $(R A)$. This procedure was designed to measure spatial working memory and was conducted in the water maze in a manner similar to PD, except that the location of the escape platform differed between sessions [i.e., the platform location differed so that the platform was in various quadrants and at different distances from the edge of the tank $(18,30$, or $42 \mathrm{~cm})]$. Within one session the platform location was constant. A session consisted of five platform trials and one probe trial, as it had in PD. The duration of each trial and ITI was the same as in PD. Because the platform location changed as of Trial 1 of each session, the measures taken during this trial reflected a search strategy that did not use any previous information as to the platform location. The improvement from Trial 1 to Trial 2 (a case in which the animals have to use their memory for the platform location obtained during Trial 1 and then match-to-location) reflected their spatial working memory. The Ratio Score was calculated for Swim Time and Swim Distance for each rat according to the following formula: (Trial $1-$ Trial 2)/Trial 1. Because Trials 3-6 of repeated acquisition did not assess working memory, but rather reference memory (Frick et al., 1995), those results were not reported and were viewed as redundant to the place discrimination task.

Cued learning $(C L)$. Cued learning was performed as a test of visual acuity. A session consisted of six platform trials, each with different platform locations in one of the four quadrants and at one of three distances from the wall of the tank: 18,30 , or $42 \mathrm{~cm}$. A visible platform ( $0.5 \mathrm{~cm}$ above the water surface) was used, and a proximal cue hung directly above the platform. The start locations were on the three axes that did not include the platform. Swim Time and Swim Distance were measured.

\section{Sensorimotor procedures (SM)}

Performance in any behavioral task can be affected by changes in such nonmnemonic abilities as motor; therefore, some measures of place discrimination may be affected if the treatment alters sensorimotor rather than mnemonic ability (Ingram, 1988; Gage et al., 1989; Gallagher and Burwell, 1989; Markowska et al., 1989; Olton et al., 1991; Davis et al., 1993). SM tests were used to assess muscle strength, coordination, and body balance of the rat. The latency to turn in an enclosed alley was a 
measure of coordination. Tests that measure both body balance and muscle strength were conducted by using two platforms connected with various types of bridges. The latency to escape to one of the two platforms was recorded, as well as the fall time when necessary. There were two rectangular bridges ( 6 and $2 \mathrm{~cm}$ in width), a round bridge, and a wire from which the rats were not permitted to escape via a platform. All sensorimotor tests have been described in detail previously (Markowska et al., 1994). The maximum latency for all tasks was 2 min. One trial of all tasks was given to each rat with an inter-trial interval of $\sim 2$ hr.

Turning in an alley. The rat was placed facing the back wall of an alley. The dependent measure was the amount of time, in seconds, that elapsed before the rat turned and faced the open end of the alley.

Bridges. The animal was placed on the escape platform of the bridge apparatus for $10 \mathrm{sec}$ and then placed in the middle of the bridge. If the rat reached the platform in under $120 \mathrm{sec}$, the latency to reach the platform was recorded and the rat was assigned a maximum latency (120 sec) to fall. Otherwise, the latency to fall was recorded, if necessary, and rat was assigned $120 \mathrm{sec}$ latency to escape. These were measured for each of the bridges: the 6 and $2 \mathrm{~cm}$ rectangular bridges and a $2-\mathrm{cm}$-in-diameter round bridge.

Wire suspension. The rat was placed, hanging by its front paws, on a horizontal wire $(0.3 \mathrm{~cm}$ in diameter $)$, and the time until the rat fell on to a cushion was recorded.

An overall $Z$-score was computed for each rat to summarize the sensorimotor performance.

\section{Estrous cycle determination}

The cytology of a vaginal sample was used to distinguish the different phases of the estrous cycle. A sample of the vaginal epithelium was obtained by lavage daily between 9:00 and 10:00 A.M. The smears were air-dried on gelatin-coated microscope slides, and the epithelial cells were stained with a commercially available Lucostat Kit (Fisher Scientific, Pittsburgh, PA). The stained samples were examined with lowpower light microscopy. Vaginal proestrous was characterized by the presence of primarily large, round, nucleated cells. Vaginal estrous was characterized by the homogeneous presence of cornified cells in the smears. Diestrus-1 was defined as the presence of leukocytes, some cornified cells, and almost no nucleated cells. Diestrus- 2 was defined by the presence of no cornified cells, a predominance of leukocytes, and some nucleated cells. The frequency of the estrous cycle was divided into three categories: (1) regular, indicating cyclicity every 4-5 d, meaning that an estrus phase or a transitional phase between proestrus and estrus was observed four or more times in a 3 week sampling period; (2) irregular, indicating longer duration of the cycle, defined as two to three instances of estrus or proestrus/estrus observed in the sample period. Females in whom the cycle lengths increased or had short and long interspersed cycles were included in this category; (3) acyclic, in which there was one/none incidence of estrus and diestrus-like smears with an increasing number of leukocyte cells or in which a constant estrus with persistent vaginal cornification was observed during the sampling period.

\section{Data analyses}

Several strategies for analyses were used to fully characterize the obtained results. First, for each task an omnibus three-way ANOVA, with repeated measures on one factor, was conducted to analyze the performance of males and females across four different ages. These $4 \times 2 \times 5$ mixed-model ANOVAs compared Age (4 vs 12 vs 18 vs 24 months) $\times$ Sex (male vs female) $\times$ Session (4 sessions for PD, 10 trials for SS, an average Ratio Scores across 4 sessions for RA, an average across all trials for CL, and an average $Z$-score for SM). Second, two focused ANOVAs were conducted to analyze the age effects for males and females separately, followed by post hoc tests. These analyses were justified by the presence of several interactions between age and sex. Third, four focused ANOVAs (Sex $\times$ Session) were conducted for each age group to compare the males and females within each age category. Fourth, separate ANOVAs (Cycling Status $\times$ Session) were conducted for each age group of females to compare performance among females with a different cyclic status. Fifth, the between-group differences in performance were analyzed further with ANCOVAs, using body weight as a covariate. In addition, the Pearson correlation was applied to analyze the relationship between body weight and sensorimotor performance. Sixth, Principal Component Analysis (PCA) and a Varimax rotation were applied into the factors with eigenvalues $>1$ to differentiate among measures of different neural systems.
Straight Swim was analyzed on swim time measures. For PCA the mean of all trials for each rat was calculated and entered as a variable. For platform trials of Place Discrimination the mean of Trials 1-5 for each of the sessions was calculated for each rat, yielding four values (one per session) for each measure and used as a repeated measure in ANOVA. For probe trials the individual probe trial measures obtained in each session were used in a data analysis. For PCA the mean of four sessions was calculated for Swim Time, Distance, Target Quadrant, Annuli-40, and Platform Crossings and was entered into the analysis. For Repeated Acquisition the Swim Time and Swim Distance ratios were averaged across all four sessions and used for all analyses. Cued Learning analyses were performed on averaged values for Swim Time and Swim Distance across all trials. Sensorimotor Skills were analyzed with a one-way ANOVA and ANCOVA, and Z-score values were used for PCA. The differences in the regularity of estrous cycle among groups were analyzed with a nonparametric test $\left(\chi^{2}\right)$.

\section{RESULTS}

\section{Subjects}

Two 24-month-old male, one 18-month-old female, and two 24month-old female rats were excluded from the study for a combination of reasons, including cataracts, tumors, or extensive weight loss. All other rats did not have observable health problems that could have interfered with testing; thus they completed all behavioral testing. One 24-month-old male rat was diving at the beginning of straight swim, and one 12 month-old male did not complete all of the sensorimotor tests; therefore, their data were excluded from the analyses.

\section{Water maze procedures}

\section{Straight swim}

A significant effect of Age $\left(F_{(3,97)}=6.3 ; p<0.001\right)$, Sex $\left(F_{(1,97)}\right.$ $=13.6 ; p<0.001)$, Age $\times$ Trial $\left(F_{(27,873)}=1.8 ; p<0.01\right)$, and Age $\times$ Sex $\times$ Trial $\left(F_{(27,873)}=1.9 ; p<0.01\right)$ interactions reflected age- and sex-related differences. These effects were attributable mainly to differences in the initial trials in the 18-month-old and 24-month-old males (Fig. 1). The separate ANOVAs performed for each sex (Age $\times$ Trials) indicated a longer Swim Time in the initial trials for the 18-month-old males (Trials $1-3$; $p$ values $<$ 0.05 ) and a longer Swim Time for the 24-month-old males (Trials $1-2 ; p<0.05)$ when compared with the 6 -month-old males. There was no Age effect in Swim Time for females across all trials.

The post hoc tests performed on each of the sexes revealed no sex differences in Swim Time within each age group, except for initial trials in the 18 -month-old rats in which the males had longer latencies than the females during Trials $1-3$ ( $p$ values $<$ $0.05)$. There was neither an Age nor a Sex effect during Trials $6-10$ ( $p$ values $>0.1$ ), suggesting no differences in swimming ability among the groups by the end of the testing.

\section{Spatial reference memory}

All groups improved their performance with training (Fig. 2, Session effect; Tables 1, 2). However, a differential rate of learning among the different age and sex groups was indicated by the presence of significant Age $\times$ Session interactions in Swim Time, Swim Distance, and all three probe trial measures.

The pattern of age-related decline in the intermediate ages was different for females than for males. The 12-month-old females performed significantly worse than the 6-month-old females in all measures, although they were not significantly different from the 18-month-old females in any of the measures (6 vs 12 and 12 vs 18; Table 2). Some additional deterioration of performance in females was observed at the age of 24 months, as compared with the 18 -month-old (18 vs 24; Table 2 ), but only in two of the six measures (Swim Time, Swim Distance). Thus, this pattern of 


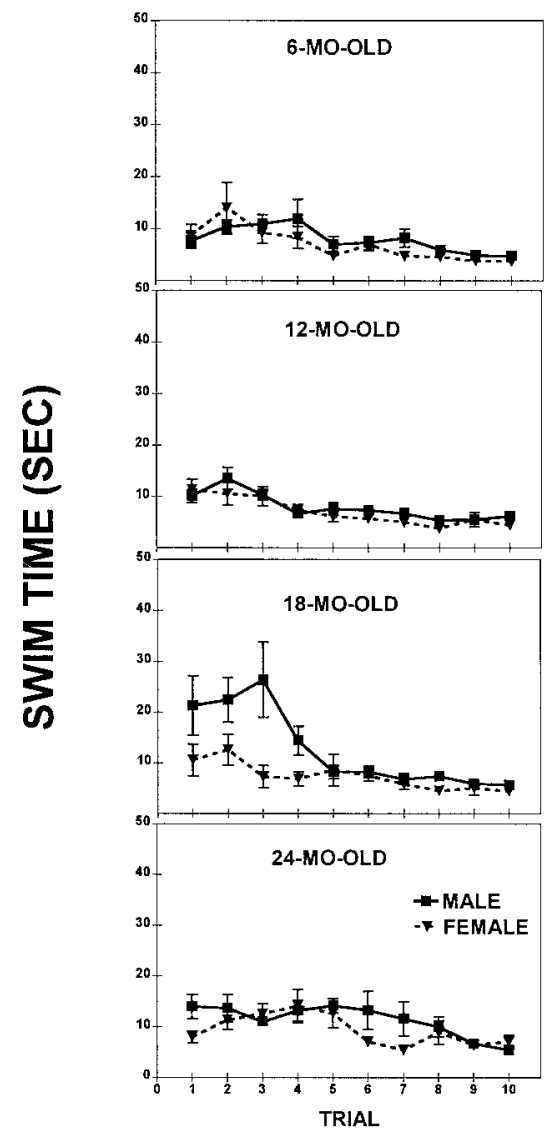

Figure 1. Straight Swim test; a comparison of the mean swim time $( \pm$ SEM) of males and females at four different ages.

change indicates that a major age-related impairment in the performance of females occurred at the age of 12 months, while no further impairment took place over the next 6 months (i.e., at the age of 18 months), with a very mild impairment at the age of 24 months.

Conversely, the performance of the 12-month-old males did not differ from that of their 6-month-old counterparts (6 vs 12 month; see Table 2) in any of the measures (except for the Platform Crossings), indicating a more preserved spatial memory ability in the 12-month-old males at an age at which the females had shown a major drop in performance. The difference in Platform Crossings was mild, although it did reach significance $(p<0.05)$. A major drop in the performance of the males occurred later in life, at the age of 18 months, and was significant in all measures of the probe trial (Target Quadrant, Annuli-40, and Platform Crossings) and in one measure of the platform trial (Distance; see Table 2). This impairment developed further, and at the age of 24 months it also appeared in the remaining two measures: Swim Time and Heading Angle. The 24-month-old males and females were impaired significantly in relation to their 6-month-old counterparts of respective sexes in all six measures (Table 2; Figs. 2, 3).

The delayed onset of the age-related changes in spatial reference memory of males was analyzed explicitly and confirmed in repeated measure ANOVAs conducted separately for each age category (Sex $\times$ Session). These analyses revealed a superior performance of males over the females in all measures, except for Swim Time $\left(F_{(1,30)}=3.6-10.4 ; 0.01<p<0.05\right)$ at the age of 12 months (Fig. 3). Interestingly, males outperformed females in Distance (Table 3, shaded area) across all ages $\left(F_{(1,18-30)}=\right.$ $4.9-13.3 ; 0.001<p<0.05)$. A closer examination of the sex differences of Distance revealed different rates of improvement for males and females (see Fig. 2). Although the females of all ages used a longer path length than the age-matched males during the initial session, they quickly improved and during the last sessions were not different from the males. In contrast to these consistent sex differences in Swim Distance, which were independent of age, the Swim Time was not different between males and females of any age group. This indicated that the females swam faster (to cover a longer distance) than did the males in the initial sessions irrespective of their age.

\section{Spatial working memory}

The age-related deficits as measured by the Swim Time and Distance ratios were present only at the age of 24 months in both males and females (Fig. 4). Although the time of onset of the impairment in spatial working memory was the same for males and females, the magnitude of the impairment was greater in females than in males. The Swim Time and Swim Distance ratios decreased with Age $\left(F_{(3,98)}=5.0\right.$ and $p<0.001 ; F_{(3,98)}=5.3$ and $p<0.001$, respectively) and were affected by $\operatorname{Sex}\left(F_{(1,98)}=4.3\right.$ and $p<0.05 ; F_{(1,98)}=6.3$ and $p<0.01$, respectively). ANOVAs performed separately on each age group demonstrated the significantly superior performance of males over the females in Swim Time and Distance ratios $(p<0.05$ and $p<0.01$, respectively) only at the age of 24 months. There were no sex differences at the ages of 6,12 , and 18 months. Independently of the rat's ability to swim (slowly or quickly), the formula for Ratio Score used the difference between the two time points and controlled for alterations in Swim Time and/or Distance to reach the platform. Therefore, the working memory impairment observed in 24-month-old rats could not be attributed to the compromised swimming ability but rather to cognitive deficits. The later onset of the working memory impairment rather than the reference memory impairment was reported previously in the repeated acquisition procedures (van der Staay and de Jonge, 1993; Frick et al., 1995) and the delayed match-to-sample in the water maze (Means and Kennard, 1991).

\section{Cued learning}

There were no Age, Sex, nor Age $\times$ Sex effects in Swim Distance. Swim Time was affected by Age $\left(F_{(1,98)}=11.1, p<0.01\right)$, but not by Sex. The Age $\times$ Sex interaction was not significant, suggesting that age-related changes in Swim Time were parallel in males and females. The post hoc tests revealed that the 24-month-old males and females had longer Swim Times than the three younger groups ( $p$ values $<0.05$ ), although their Swim Distance was not significantly different from that of their younger counterparts (Table 4). This pattern of results suggests that older rats were able to reach the platform within the shortest paths. Alternatively, the old rats were slower because of a "decision-making" or an "energy-conserving" strategy. Nevertheless, a clarification of this finding requires further study. More importantly, the deficit in Swim Time observed in the 24-month-old rats could not contribute to the pattern of age-related alterations in the spatial reference memory and spatial working memory, because the major drop in performance in the reference memory task was observed earlier, whereas in the working memory task the measures were independent of swimming abilities (Ratio Scores). 


\section{PLATFORM TRIAL MEASURES}

MALES
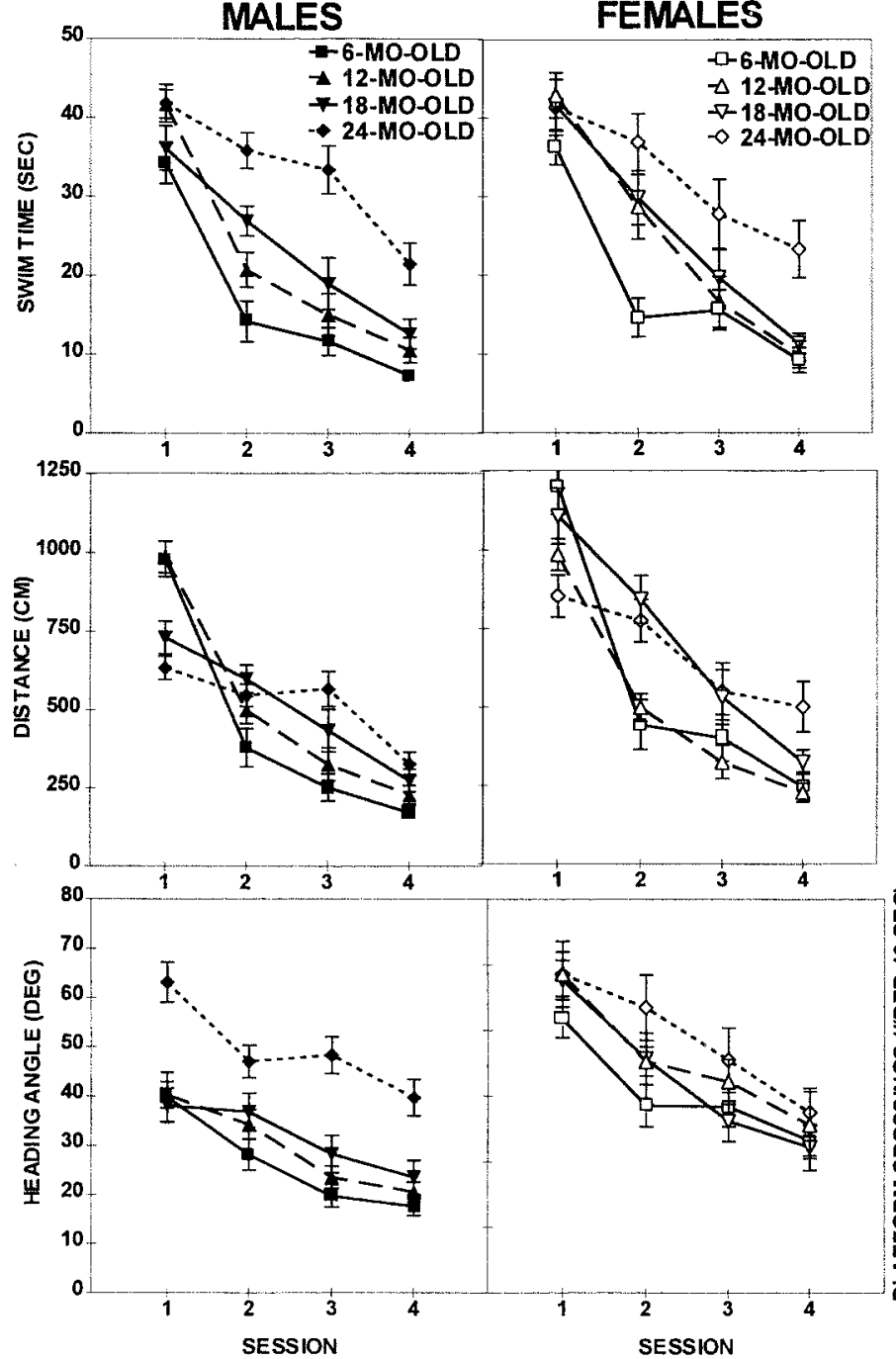
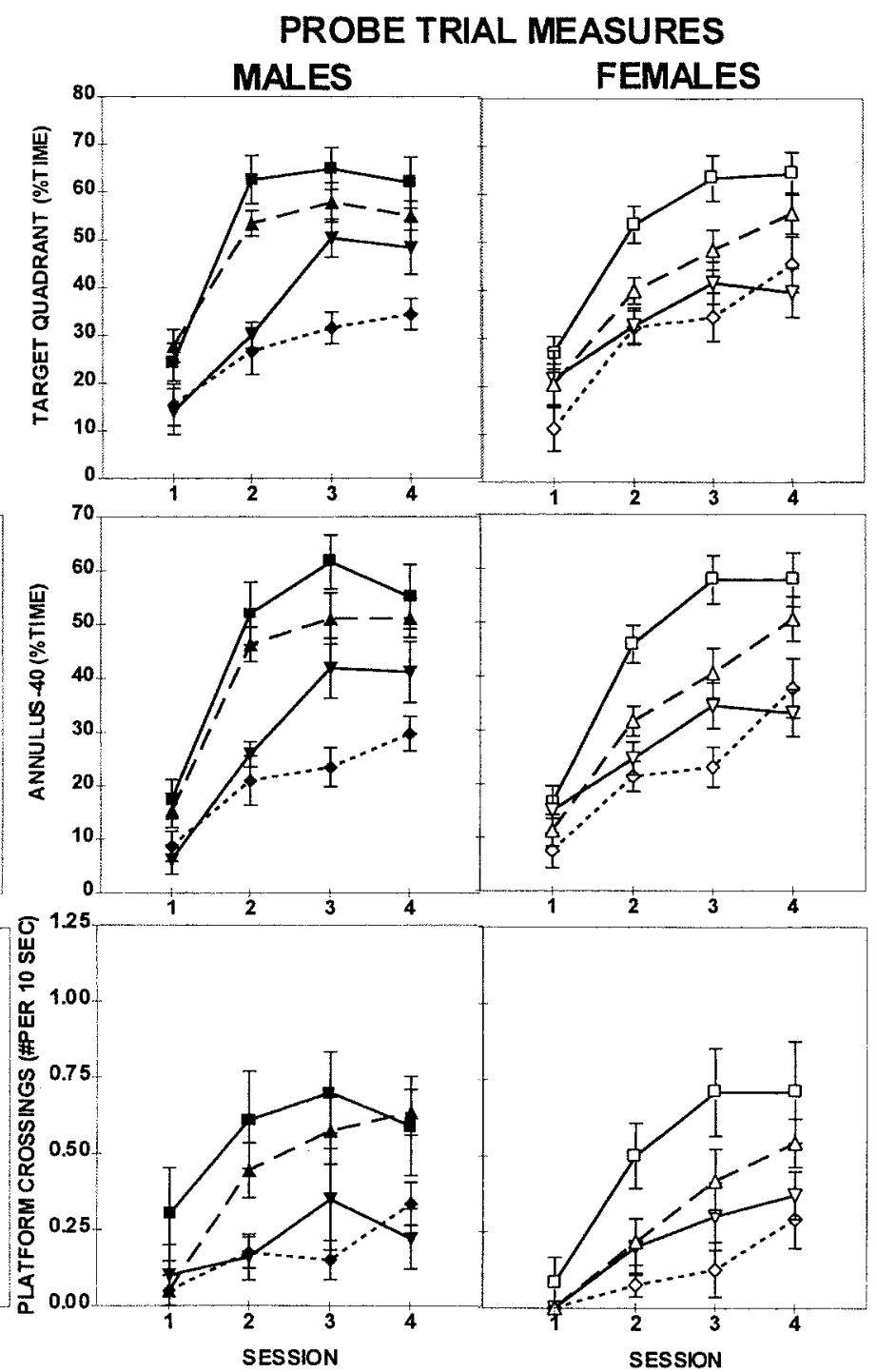

Figure 2. Place discrimination in the water maze; a comparison of the mean performance ( \pm SEM) of males ( filled symbols) and females (open symbols) across sessions in platform trial measures (two left columns): swim time (top), swim distance (center), and heading angle (bottom) and in probe trial measures (two right columns): target quadrant (top), annulus-40 (center), and platform crossings (bottom).

Table 1. Omnibus ANOVA (Age $\times$ Sex $\times$ Session) results for the place discrimination task

\begin{tabular}{|c|c|c|c|c|c|c|c|}
\hline & Age & Sex & Age $\times$ Sex & Sessions & Age $\times$ Session & Sex $\times$ Session & Age $\times$ Sex $\times$ Session \\
\hline Variable & $F_{3,98}$ & $F_{1,98}$ & $F_{3,98}$ & $F_{3,294}$ & $F_{9,294}$ & $F_{3,294}$ & $F_{9,294}$ \\
\hline Swim time & $20.4 x x x$ & 1.1 & 0.3 & $175.5 x x x$ & $5.0 x x x$ & 0.7 & 0.9 \\
\hline Swim dist & 2.1 & $29.5 x x x$ & 0.2 & $240.1 x x x$ & $15.7 x x x$ & $7.1 x x x$ & 1.3 \\
\hline Head ang & $13.8 x x x$ & 0.1 & $4.4 x x$ & $71.6 x x x$ & 0.4 & 0.2 & 1.4 \\
\hline Targ. quad. & $34.3 x x x$ & 0.8 & 1.9 & $91.1 x x x$ & $1.9 x$ & 0.8 & 1.4 \\
\hline Annuli-40 & $31.5 x x x$ & 1.6 & 1.2 & $116.6 x x x$ & $3.9 x x x$ & 1.7 & 0.9 \\
\hline Plat cross & $21.8 x x x$ & 2.5 & 0.7 & $25.8 x x x$ & $1.8 x$ & 0.9 & 0.4 \\
\hline
\end{tabular}

$x x x, x x, x$ represent a difference at $p<0.001, p<0.01, p<0.05$, respectively.

\section{Sensorimotor skills}

Performance in sensorimotor tasks (Fig. 5) declined with age $\left(F_{(3,97)}=3.8-30.8 ; 0.01<p<0.001\right)$. The females outperformed the males in the majority of sensorimotor tasks, and these effects reached significance as indicated by the Sex Effects $\left(F_{(1,97)}=\right.$ $2.0-36.7 ; 0.08<p<0.001)$ and Sex $\times$ Age interactions $\left(F_{(3,97)}=\right.$
2.5-3.8; $0.05<p<0.01)$. At an age as young as 6 months the superior performance of females was already evident in a majority of the tasks, and this superiority was maintained until the age of 24 months. At 24 months of age the performance of both females and males further declined and reached similar levels, as judged by the overall $Z$-score computed from all of the tasks. 
Table 2. Focused ANOVA (Age $\times$ Session) results for the place discrimination task

\begin{tabular}{|c|c|c|c|c|c|c|c|c|c|c|}
\hline \multirow[b]{2}{*}{ Variable } & \multirow[b]{2}{*}{ Sex } & \multirow{2}{*}{$\begin{array}{l}\text { Age } \\
F_{3,56}(\mathrm{~m}) \\
F_{3,42}(\mathrm{f})\end{array}$} & \multirow{2}{*}{$\begin{array}{l}\text { Sessions } \\
F_{3,168}(\mathrm{~m}) \\
F_{3,126}(\mathrm{f})\end{array}$} & \multirow{2}{*}{$\begin{array}{l}\text { Age } \times \\
\text { Session } \\
F_{9,168}(\mathrm{~m}) \\
F_{9,126}(\mathrm{f})\end{array}$} & \multicolumn{6}{|c|}{ Post hoc comparisons } \\
\hline & & & & & 6 vs 12 & 6 vs 18 & 6 vs 24 & 12 vs 18 & 12 vs 24 & 18 vs 24 \\
\hline \multirow[t]{2}{*}{ Swim time } & $\mathrm{m}$ & $14.0 x x x$ & $110.4 x x x$ & $4.5 x x x$ & & & $x x x$ & & $x x x$ & $x$ \\
\hline & $\mathrm{f}$ & $8.1 x x x$ & $69.4 x x x$ & $2.2 x$ & $x$ & $x$ & $x x x$ & & $x x x$ & $x x$ \\
\hline \multirow[t]{2}{*}{ Swim distance } & $\mathrm{m}$ & 0.8 & $135.9 x x x$ & $12.8 x x x$ & & $x x x$ & $x x x$ & $x x$ & $x x x$ & \\
\hline & $\mathrm{f}$ & 1.3 & $105.2 x x x$ & $6.0 x x x$ & $x$ & $x$ & $x x x$ & & $x x x$ & $x x$ \\
\hline \multirow[t]{2}{*}{ Head angle } & $\mathrm{m}$ & $8.0 x x x$ & 1.5 & 0.6 & & & $x x$ & & $x x$ & $x x$ \\
\hline & $\mathrm{f}$ & 1.0 & $5.8 x x x$ & $1.9 x$ & & & $x$ & & & \\
\hline \multirow[t]{2}{*}{ Targ quad } & $\mathrm{m}$ & $27.9 x x x$ & $47.3 x x x$ & $2.3 x$ & & $x x x$ & $x x x$ & $x x x$ & $x x x$ & $x$ \\
\hline & $\mathrm{f}$ & $12.5 x x x$ & $46.6 x x x$ & 1.1 & $x$ & $x x x$ & $x x x$ & & & \\
\hline \multirow[t]{2}{*}{ Annuli-40 } & $\mathrm{m}$ & $20.3 x x x$ & $61.0 x x x$ & $2.6 x x$ & & $x x$ & $x x x$ & $x$ & $x x x$ & \\
\hline & $\mathrm{f}$ & $15.7 x x x$ & $61.9 x x x$ & $2.7 x x$ & $x x$ & $x x x$ & $x x x$ & & $x$ & \\
\hline \multirow[t]{2}{*}{ Plat cross } & $\mathrm{m}$ & $12.9 x x x$ & $9.3 x x x$ & 1.4 & & $x x$ & $x x x$ & $x$ & $x x$ & \\
\hline & $\mathrm{f}$ & $10.7 x x x$ & $19.2 x x x$ & 1.1 & $x x$ & $x x$ & $x x x$ & & & \\
\hline
\end{tabular}

$x x x, x x, x$ represent a difference at $p<0.001, p<0.01, p<0.05$, respectively.

$\mathrm{m}=$ males; $\mathrm{f}=$ females.

However, sex differences, although much milder, were still present in a couple of individual sensorimotor tasks: Turn in an Alley and Fall from the $2 \mathrm{~cm}$ Bridge. Performance in these tasks, which assessed coordination and body balance, was better in 24-month-old females than in males. However, when the tasks became more demanding and required muscle strength, such as a Wire Suspension or a Round Bridge, the females were not different from the males.

This pattern of age-dependent and sex-dependent changes was reflected by the $Z$-scores, indicating that, although the overall sensorimotor performance declined with age $\left(F_{(3,97)}=32.7 ; p<\right.$ $0.001)$, the pattern of this decline differed between sexes, as suggested by the Sex Effect $\left(F_{(1,97)}=34.8 ; p<0.001\right)$ and the Sex $\times$ Age interaction $\left(F_{(3,97)}=3.4 ; p<0.01\right)$. The overall superior performance of females was significant at 6 months $(p<$ $0.001), 12$ months $(p<0.001)$, and 18 months $(p<0.01)$, but not at 24 months of age, at which point the males and females performed at a similar level. More importantly, at the age of 12 months the females did not have any impairment in sensorimotor skills and were superior to males, yet they were inferior in reference memory performance, suggesting that this cognitive deficit was not attributable to nonmnemonic factors. Similarly, at 24 months of age, the females were not worse than the males in overall sensorimotor scores, although they were inferior in working memory tasks.

The body weight of males was greater than that of the females across the entire life span [Fig. 6, Sex Effect $\left(F_{(1,98)}=1040.5 ; p<\right.$ $0.001)]$. Body weight changed with age (Age Effect, $F_{(3,98)}=25.9$; $p<0.001)$. However, whereas the body weights of females increased gradually, the males reached a plateau at the age of 12 months, and their body weights generally did not change afterward.

After the body weight was factored out in ANCOVA (Age $\times$ Sex), the sex differences decreased and became nonsignificant, suggesting that body weight contributed as a factor in a majority of the sensorimotor tasks. Only sex differences in two tasks, Turn in an Alley and Fall from a $6 \mathrm{~cm}$ Bridge, were still significant, indicating that they were independent of the body weight. Interestingly, the performance deteriorated somewhat faster in the females so that by the age of 24 months it did not differ from that
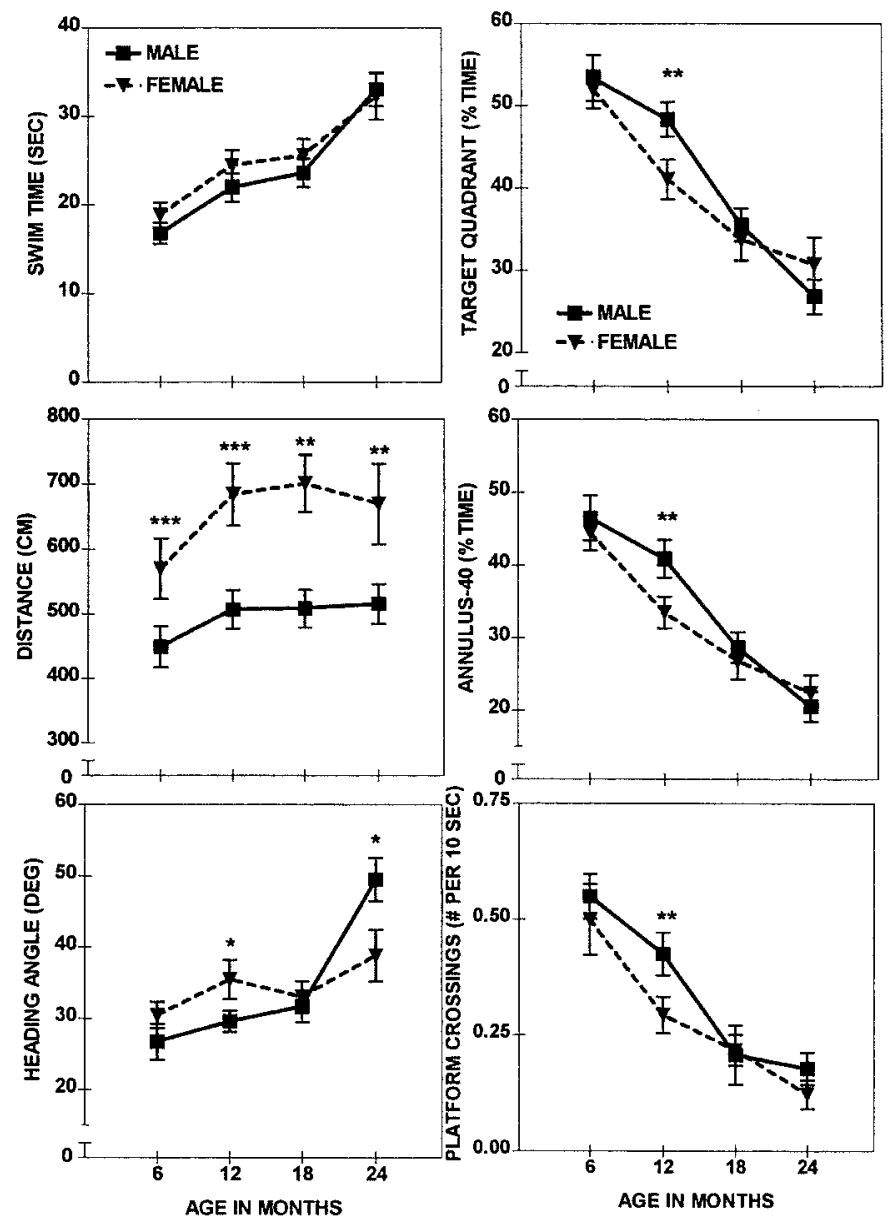

Figure 3. Place discrimination in the water maze; a comparison of the session averages ( \pm SEM) of males (solid line) and females (dashed line) across four different ages. Shown are significant sex differences at ${ }^{* * *} p<$ $0.001,{ }^{*} p<0.01,{ }^{*} p<0.05$. 
Table 3. Focused ANOVA $($ Sex $\times$ Session) results for the place discrimination task

\begin{tabular}{|c|c|c|c|c|c|c|c|c|c|c|c|c|}
\hline \multirow[b]{2}{*}{ Variable } & \multicolumn{3}{|c|}{6 Month old } & \multicolumn{3}{|c|}{12 Month old } & \multicolumn{3}{|c|}{18 Month old } & \multicolumn{3}{|c|}{24 Month old } \\
\hline & $\begin{array}{l}\text { Sex } \\
F_{1,20} \\
\end{array}$ & $\begin{array}{l}\text { Session } \\
F_{3,60}\end{array}$ & $\begin{array}{l}\text { Sex } \times \\
\text { Session } \\
F_{1,30} \\
\end{array}$ & $\begin{array}{l}\text { Sex } \\
F_{1,30} \\
\end{array}$ & $\begin{array}{l}\text { Session } \\
F_{3,90}\end{array}$ & $\begin{array}{l}\text { Sex } \times \\
\text { Session } \\
F_{3,90} \\
\end{array}$ & $\begin{array}{l}\text { Sex } \\
F_{1,18} \\
\end{array}$ & $\begin{array}{l}\text { Session } \\
F_{3,54}\end{array}$ & $\begin{array}{l}\text { Sex } \times \\
\text { Session } \\
F_{3,54} \\
\end{array}$ & $\begin{array}{l}\text { Sex } \\
F_{1,30} \\
\end{array}$ & $\begin{array}{l}\text { Session } \\
F_{3,90}\end{array}$ & $\begin{array}{l}\text { Sex } \times \\
\text { Session } \\
F_{3,90} \\
\end{array}$ \\
\hline Time & 1.2 & $72.5 x x x$ & 0.3 & 1.1 & $83.8 x x x$ & 1.5 & 0.6 & $43.9 x x x$ & 0.7 & 0.1 & $21.6 x x x$ & 0.9 \\
\hline Dist & $4.9 x$ & 93.2 $x x x$ & 0.8 & $10.4 x x$ & 109.6 $x x x$ & $4.0 x x x$ & 13.3 $x x x$ & $39.8 x x x$ & $3.0 x$ & $6.0 x$ & 23.1 $x x x$ & $3.8 x$ \\
\hline Ang & 2.1 & $21.8 x x x$ & 0.9 & $4.2 x$ & $22.6 x x x$ & 0.8 & 0.2 & $15.8 x x x$ & 1.5 & $4.9 x(f)$ & $18.8 x x x$ & 1.3 \\
\hline QQ & 0.1 & $39.1 x x x$ & 0.8 & $4.9 x$ & $36.2 x x x$ & 1.7 & 0.3 & $15.6 x x x$ & 1.6 & 1.0 & $14.3 x x x$ & 1.4 \\
\hline PAB & 0.2 & $43.7 x x x$ & 0.5 & $3.6 x$ & $50.2 x x x$ & 1.7 & 0.3 & $20.4 x x x$ & 1.8 & 0.2 & $16.7 x x x$ & 0.6 \\
\hline ONC & 0.3 & $5.3 x x$ & 0.5 & $4.0 x$ & $16.9 x x x$ & 0.4 & 0.01 & $3.2 x$ & 0.6 & 1.1 & $7.1 x x x$ & 0.12 \\
\hline
\end{tabular}

Bold areas represent a superior performance of males over females.

$x x x, x x, x$ represent a difference at $p<0.001, p<0.01, p<0.05$, respectively.
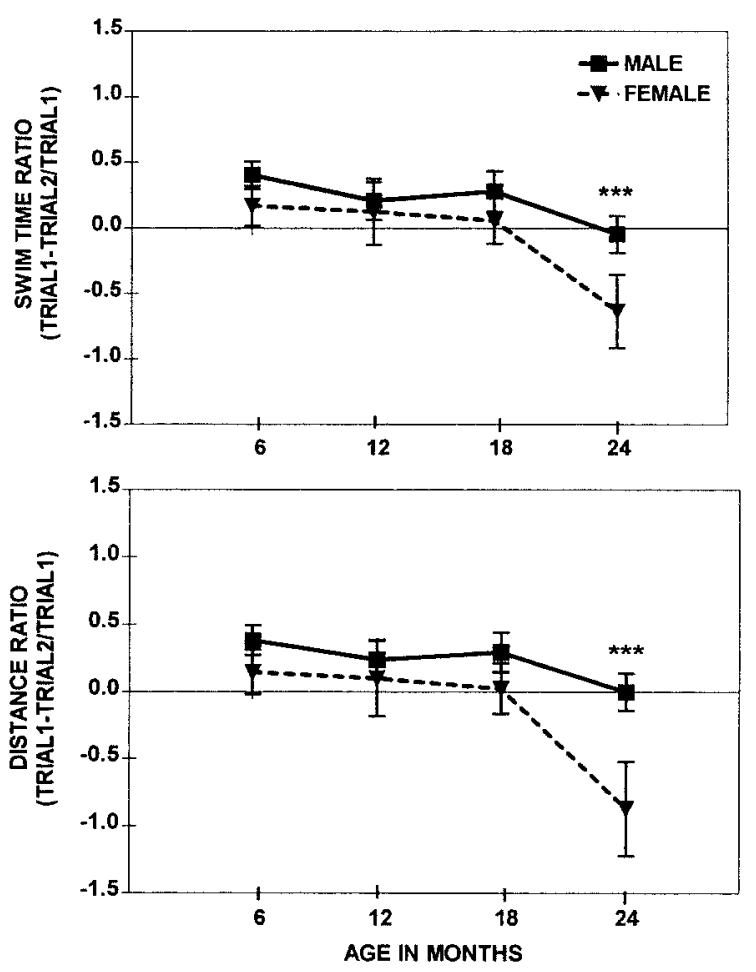

Figure 4. Repeated acquisition in the water maze; a comparison of the session averages $( \pm$ SEM) from swim time ratio and swim distance ratio of males and females across four different ages. ${ }^{* * *}$ Sex differences at $p<$ 0.001 between 14-month-old males and females.

of the males, whereas the differences in the body weight still persisted. Importantly, at the age of 24 months the performance did not yet reach the minimum level. Therefore, this effect could not be related to the floor effect. Most likely, at this point the lower body weight of the females was no longer advantageous to the performance in the sensorimotor tasks. The results of the Pearson correlation (Fig. 7) between the overall sensorimotor performance ( $Z$-score) and standardized body weight suggested a similar significant relationship in both sexes $(p$ values $<0.001)$ yet a less robust correlation in males $(r=-0.31)$ than in females $(r=-0.66)$. Taken together, the differences in body weight contributed to the superior performance of the females. Nevertheless, other factors, including body mass composition and muscle strength, should not be ruled out completely, because they could have contributed to sex differences as well.

\section{Estrous cycle}

During the aging process the female rat's regular 4-5 d estrous cycle was replaced by an irregular cycle, which was followed by acyclicity, when the female ceases to cycle (Fig. 8). The transition to lengthening cycles was apparent at the age of 12 months. The decreasing frequency and increasing variability of the estrous cycle is a characteristic of aging in rats (Finch et al., 1984). At 6 months of age all of the females cycled, with a majority of them (83\%) going into the cycle regularly, every $4-5 \mathrm{~d}$, whereas the remaining $17 \%$ showed a less regular pattern of cycling. As the females grew older, this irregular cycle became predominant, as observed in the 12-month-old females: only $30 \%$ cycled regularly, whereas $60 \%$ had a prolonged duration of cycles. The incidence of longer cycles increased with age during the approach to acyclicity. Shorter cycles occurred sporadically, even just before acyclicity; very often the short and long cycles were interspersed. While acyclicity approached, constant estrous, followed by persistent diestrus or persistent diestrus only, was observed. In one 12-month-old female rat, persistent vaginal cornification was observed for a prolonged period of time, and this female was qualified as acyclic. At 18 months of age none of the females exhibited regular cycles; $40 \%$ qualified as acyclic, with a majority of them exhibiting the diestrus-type of smear and one case exhibiting constant estrus (all $21 \mathrm{~d}$ ). At 24 month of age, $75 \%$ of the females' estrous cycling ceased completely, whereas irregular cycling was observed in the remaining $25 \%$ of the animals. The nonparametric $\chi^{2}$ test, comparing the percentage of rats in each cyclic category, revealed a significant difference among the four age groups $\left(\chi^{2}=310.5 ; \mathrm{df}=6 ; p<0.0001\right)$. The general pattern of reproductive senescence observed in the present study was consistent with previous findings (LeFevre and McClintock, 1988, 1991).

Separate ANOVAs were conducted to compare performance in Place Discrimination among females with a different cyclic status (Session $\times$ Cyclic Status). The effect of Cyclic Status did not reach a significant level $(p>0.05)$. This was partially attributable to the fact that the number of animals representing each of the cyclic categories was low, thus decreasing the sensitivity of statistical analyses. In addition, not all of the cyclic categories were represented in each of the age groups, therefore impeding the execution of a more powerful overall analysis with all of the age groups. Although differences in performance among females exhibiting a different cyclic category did not reach a significant level, there were some trends (Fig. 9). For instance, in the group of 12-month-old females the best performance as judged by the 
Table 4. F-344: Summary of results from cued learning for each age group

\begin{tabular}{|c|c|c|c|c|c|}
\hline \multirow[b]{2}{*}{ Age } & \multirow[b]{2}{*}{$n$} & \multicolumn{2}{|c|}{ Swim time (sec) } & \multicolumn{2}{|l|}{ Distance $(\mathrm{cm})$} \\
\hline & & Male & Female & Male & Female \\
\hline 6 month old & 22 & $5.3 \pm 0.3$ & $5.9 \pm 0.5$ & $168.3 \pm 12.4$ & $180.9 \pm 15.7$ \\
\hline 12 month old & 32 & $5.2 \pm 0.2$ & $5.5 \pm 0.3$ & $172.7 \pm 43.1$ & $170.8 \pm 10.4$ \\
\hline 18 month old & 20 & $7.2 \pm 0.3$ & $7.3 \pm 1.1$ & $162.4 \pm 11.6$ & $197.4 \pm 29.3$ \\
\hline 24 month old & 32 & $14.6 \pm 2.1 x$ & $11.5 \pm 2.8 x$ & $182.0 \pm 18.9$ & $241.4 \pm 74.7$ \\
\hline
\end{tabular}

Values represent the mean \pm the SEM.

$x$ represents a difference at $p<0.05$ between 24 month old and three other age groups within each sex category.
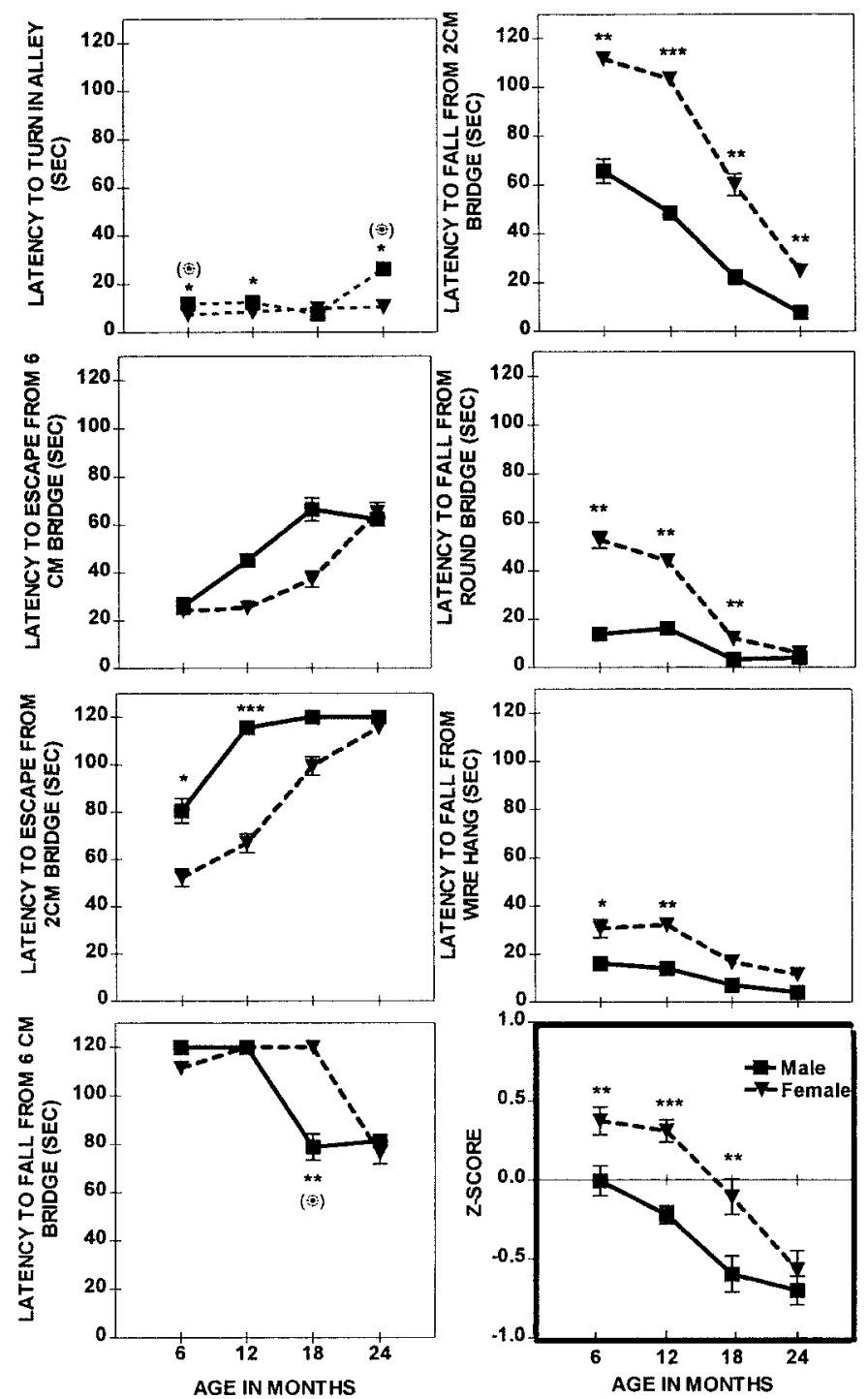

Figure 5. Sensorimotor skills; a comparison of the mean performance $( \pm \mathrm{SEM})$ of males (solid line) and females (dashed line) across four different ages. Shown are significant sex differences at ${ }^{* * *} p<0.001,{ }^{* *} p<$ 0.01 , and ${ }^{*} p<0.05$, respectively, in the ANOVA and $(\odot)$ at $p<0.05$ in the ANCOVA.

time in the Target Quadrant was attributed to the females with regular estrous cycles. The worst, on the other hand, was seen in the acyclic female, whereas females with an irregular cycle were intermediate performers. Similar trends were observed in each of the age groups of the females, suggesting that, within each age

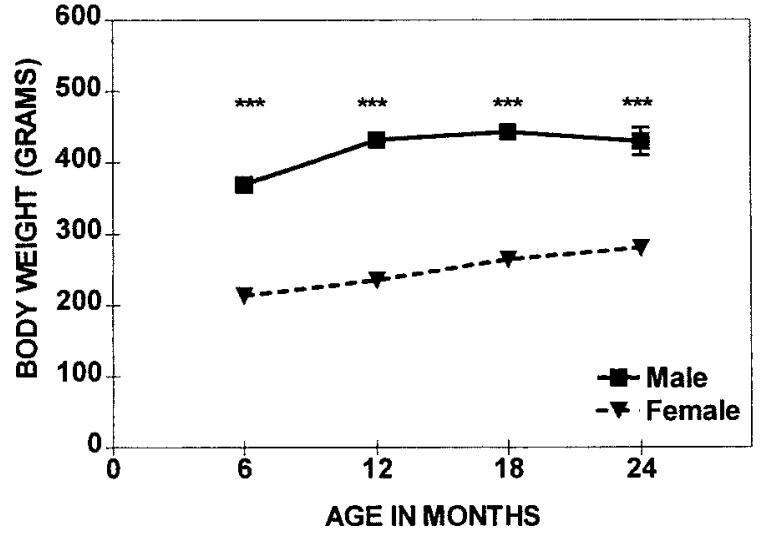

Figure 6. Comparison of the mean body weight ( \pm SEM) of females and males across four ages. Shown are significant sex differences at $* * * p<$ 0.001 .

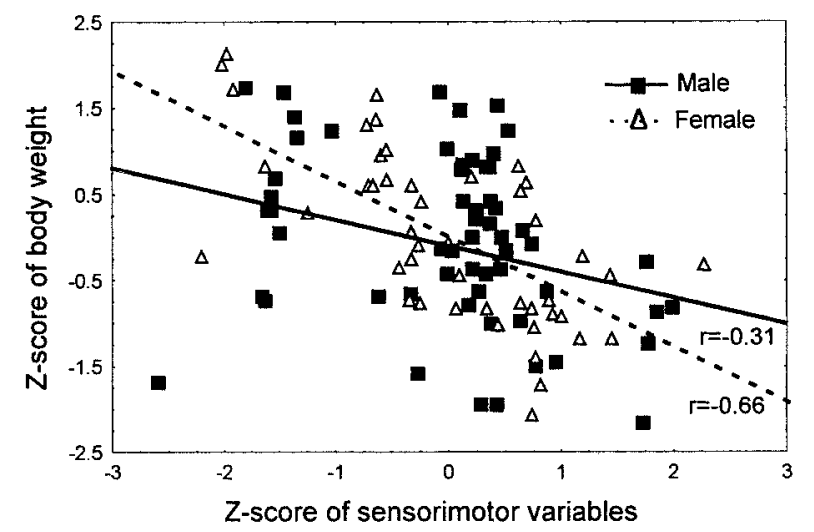

Figure 7. Relationship between body weight and performance in sensorimotor tasks in males (solid line) and females (dashed line). The lines represent results from Pearson correlations, significant at $p<0.001$. Symbols in the scatter plots represent the data for the individual animals.

group, females with less compromised endocrine status performed somewhat better than the ones experiencing greater hormone alterations.

\section{Principal component analysis}

The Principal Component Analysis yielded four significant factors with eigenvalues $>1$; the percentage of variance explained by the components was $42,17,14$, and $9 \%$, respectively. The pattern of rotated loadings onto the same factor allowed for the detection of variables that measured similar aspects of behavior. Measures of cued tasks, latency and distance, loaded highly onto Factor 1 $(0.94,0.88)$. Body weight, Swim Time in SS, and $Z$-scores from 


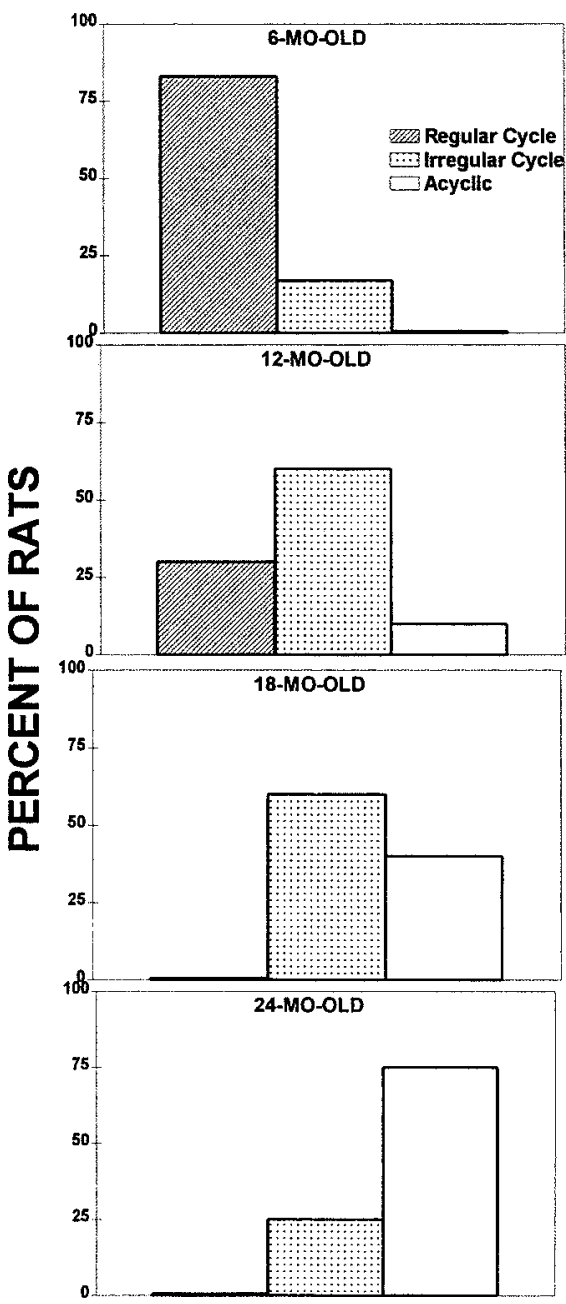

Figure 8. Regularity of estrous cycle at four different age groups.

SM loaded onto Factor $2(0.76,-0.75,0.67)$. Working memory measures, Swim Ratio and Distance Ratio, loaded very highly onto Factor $3(0.96,0.96)$. All measures of spatial reference memory except for Swim Distance loaded onto Factor 4: Annuli-40 (0.88), Platform Crossings (0.86), Target Quadrant (0.85), and Swim Time $(-0.75)$. Swim Distance did not load highly onto any of the factors, with loadings onto Factor $1(0.51)$, Factor $2(0.48)$, and Factor $4(-0.57)$. This separation of measures from different tasks loading onto different factors indicates that, indeed, they do reflect different aspects of behavior. The measures that were loading highly onto the same factor were considered related and seen as reflecting similar aspects of behavior.

\section{DISCUSSION}

The results of the present experiment documented a differential effect of the aging process on different types of spatial memory and sensorimotor skills in male and female rats. In each of these domains a distinct pattern of age-related interactions with sex differences emerged, suggesting a different sensitivity to the aging processes of the neural mechanisms involved in their function. The results of the principal component analyses, which indicated that measures from the reference memory task, the working memory task, and the sensorimotor tasks loaded primarily onto different factors, supported this view, thereby suggesting that each
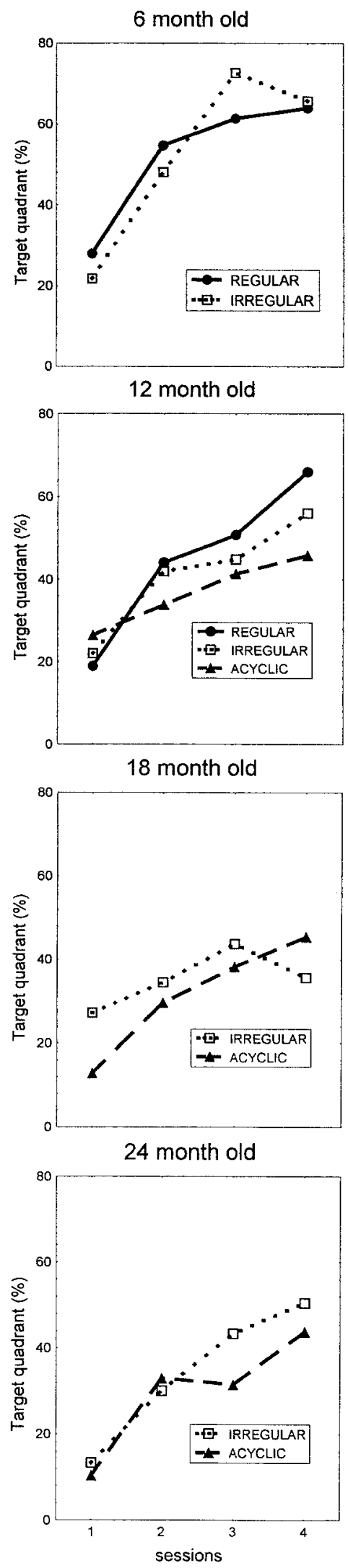

Figure 9. Place discrimination in the water maze (Target Quadrant measure); a comparison of the session averages ( \pm SEM) of females with a different cyclic status at four different age groups. 
of these tasks measured different aspects of behavior maintained by different neural processes.

In particular, the present study found sex differences in the rate of development and the magnitude of age-related impairments in spatial reference memory. Although there were no sex differences at the age of 6 months, the onset of age-related decline took place earlier in the females, resulting in sex differences at the age of 12 months. The onset of age-related changes occurred more gradually in males, with a very mild impairment at the age of 12 months and progressively greater decline at the age of 18 months to an even more severe impairment at the age of 24 months. Overall, aging significantly affected the performance of both males and females with a different time of onset and magnitude. However, at the age of 18 months and older, animals of both sexes experienced severe memory deficits and were not different from each other.

Several studies previously have reported age-related impairments in spatial memory tested in the Morris water maze in male (Markowska et al., 1989, 1994; Frick et al., 1995; Markowska, 1999; Markowska and Breckler, 1999) as well as in female rats (Gage et al., 1989; Fischer et al., 1991). However, none of these studies has compared systematically the age dependence and dynamic of these changes between the two sexes. Previously, in a study on Fischer-344, we reported a similar pattern of age-related changes in spatial reference memory, but that study did not include female rats (Frick et al., 1995). Although several studies have reported somewhat different degrees of impairment or varied rates of decline in other strains of rats (Fischer et al., 1991), it seems likely that some differences reflected the relatively shorter life span of the Fischer-344 when compared with Sprague Dawley rats, for example. Several other factors also could contribute to some of the discrepancies, including previous experience of females (virgin vs retired breeders) and, in particular, procedural differences between the studies (e.g., different types of probe trial).

The results of the present study are consistent with findings reporting a lack of sex differences in water maze performance in young Long-Evans rats (Bucci et al., 1995; Warren and Juraska, 1997). On the other hand, the present data contradict the finding obtained from young Sprague Dawley rats, which reported the superior performance of males in the water maze (Roof, 1993). In the present study the lack of sex differences in young 6-month-old F-344 rats was observed in both types of spatial memory. At 6 months of age the only sex difference in performance of the place discrimination task was observed in Swim Distance. Males performed better in the early sessions and maintained their superiority across all tested ages, indicating that they consistently took a shorter path to the platform from the very beginning of testing, whereas the females did not. Conceivably, the females were less focused in reaching the platform at the beginning of training. However, they gradually learned to minimize their Swim Distance, and by the end of training their Distance to reach the platform was similar to that of the males. While navigating through the maze, the males and females might have used different spatial cues: geometry of the room or both landmarks and geometry cues, respectively (Williams et al., 1990). Perhaps the differences in associational-perceptual processes, which guide the spatial ability, contributed to the initial sex differences in Swim Distance.

Other studies suggested that female rats could rely more heavily than the males on the available odor trails, even in the water maze situation (Means et al., 1992). In that light, the females could have been more distracted during the early ses- sions, if they indeed tried to use the preferable but ambiguous cues of odor trails for locating the escape platform. This rather inefficient strategy in the present experimental situation perhaps could result in the longer Swim Distances to find the platform. In this respect, this result is consistent with the view that the Swim Distance in the Morris water maze is not a pure measure of cognitive function (Lindner, 1997). In any case, sex differences in Swim Distance in young F-344 rats are more likely to reflect some differences in performance, perhaps related to the different strategies, rather than to cognition. The finding, that by the end of everyday training both males and females were covering a similar Distance to get to the platform, indicates that females did have the capability of using the most efficient spatial strategy, but clearly they required more training to develop it. More importantly, in the present study the probe trial measures more accurately reflected sex differences in cognition, because these measures were not confounded by the nonmnemonic factors and were more sensitive to the aging process (Markowska et al., 1993; Frick et al., 1995). In both sexes all probe trial measures were affected by the aging process earlier in life and to a greater degree than the platform trial measures. This finding is consistent with our previous observations (Markowska et al., 1993; Frick et al., 1995). The suggestion that the Swim Distance is the most appropriate measure of cognitive function in the Morris water maze (Lindner, 1997) is not confirmed by the present study. In addition, all measures from the probe trial loaded very highly onto the separate factors (PCA) than the nonmnemonic measures, including sensorimotor skills, body weight, and swimming ability, indicating that indeed the probe trial measures were independent from nonmnemonic ones. Furthermore, the superiority of the probe trial in measuring cognitive function also may be related to the fact that the platform trials offered the rat a number of strategies, not necessarily spatial ones, to find the platform. Such strategies might include circling the tank at a certain distance from the edge of the tank to locate the platform, velocity of swim, etc. In contrast, none of the probe trial measures was confounded by swim speed simply because an accurate rat with slow swim speed could still score well on any of the probe trial measures. Moreover, the probe trials do not offer alternatives to the spatial strategy. Thus, these measures assess the accuracy of spatial memory rather than the effectiveness of strategies in finding the platform (Markowska et al., 1993).

The present study also revealed the existence of sex differences in spatial working memory as assessed in the repeated acquisition task. However, it cannot be ruled out that a more demanding working memory task would have detected an impairment earlier than at 24 months (Kadar et al., 1990; Olton and Shapiro, 1992). The deficit in Swim Time observed in the 24-month-old rats in the cued task could not contribute to the pattern of age-related alterations in spatial reference and spatial working memory for two reasons: first, because the decline in reference memory was observed much earlier; second, because measures of working memory were independent from speed/distance (Ratios). In addition, the pattern of sex differences in sensorimotor function indicated opposite superiority: females outperforming the males in a majority of the tasks. Taken together, the greater deficits observed in reference and working memory in the females seem to be cognitive in origin and not attributable to alterations in sensory and motor abilities as assessed by the straight swim, cued task, and sensorimotor tasks.

It is important to emphasize that the body weight of males was greater than that of the females across the entire life span. After 
the body weight was covaried (ANCOVA), the sex differences in sensorimotor performance were no longer significant, as expressed by the overall $Z$-score. This suggests that the lower body weight contributed to the superior performance of the females. However, at 24 months of age, despite the greater body weight of the males, the performance of the females was no longer superior, indicating that the decline in sensorimotor skills reached a similar level in both sexes. In addition, a stronger negative correlation between body weight and sensorimotor performance was detected in females rather than in males, pointing to other factors that also could contribute to these differences, such as body mass composition or muscle strength.

The female brain reacts rapidly to variations in ovarian hormones (Gould et al., 1990; Woolley et al., 1990; Woolley and McEwen, 1993; McEwen et al., 1997). As the estrous cycle becomes less regular with reproductive senescence, natural fluctuations of estrogen are altered in both plasma levels and brain uptake (LeFevre and McClintock, 1988). In the present study, alterations in the estrous cycle regularity were revealed as early as the age of 12 months. These data are consistent with other studies demonstrating that estropause in the rat begins at $\sim 9-12$ months of age (Finch et al., 1984). Later, the females enter either persistent estrus or persistent diestrus, followed by anestrus (Dudley, 1982). Because the onset of reference memory impairment occurred in the females at the age of 12 months, it is a possibility that at least some of the alterations in neural processes implicated in memory that occur as a consequence of aging were accelerated by altered estrogen levels. Consequently, estrogen disturbances and the subsequent decline in levels may well contribute to the earlier onset and a more pronounced deficit of memory seen in the females. This is in line with the observation that females with less compromised endocrine status performed somewhat better than the ones experiencing greater hormone alterations. Similarly, the finding indicating that in aged female monkeys, reproductive senescence predicted cognitive decline (Roberts et al., 1997) is consistent with the outcome of the current study. Thus, results showing sex differences in the rate of age-related cognitive impairments might reflect additive or interactive deficits from both aging and the alterations in the hormonal milieu. However, the degree to which hormonal alterations affect age-related declines in cognitive performance and whether the observed correlations are causal in origin require further study.

\section{REFERENCES}

Archer J (1979) Inbreeding and sex differences in rats and mice: a rejoinder to Gray. Br J Psychol 70:37.

Beatty WW (1979) Gonadal hormones and sex differences in nonreproductive behaviors in rodents: organizational and activational influences. Horm Behav 12:112-163.

Berger-Sweeney J, Arnold A, Gabeau D, Mills J (1995) Sex differences in learning and memory in mice: effects of sequence of testing and cholinergic blockade. Behav Neurosci 109:859-873.

Bucci DJ, Chiba AA, Gallagher M (1995) Spatial learning in male and female Long-Evans rats. Behav Neurosci 109:180-183.

Coleman PD, Finch CE, Joseph JA (1990) The need for multiple time points in aging studies. Neurobiol Aging 11:1-2.

Collins DW, Kimura D (1997) A large sex difference on a twodimensional mental rotation task. Behav Neurosci 111:845-849.

Crook T, Bartus RT, Ferris SH, Whitehouse P, Cohen GD, Gershon S (1986) Age-associated memory impairment: proposed diagnostic criteria and measures of clinical change - report of a National Institute of Mental Health work group. Dev Neuropsychol 2:261-276.

Davis S, Markowska AL, Wenk GL, Barnes CA (1993) Acetyl-L-carnitine: behavioral, electrophysiological, and neurochemical effects. Neurobiol Aging 14:107-115.

Delgado AR, Prieto G (1996) Sex differences in visuospatial ability: do performance factors play such an important role? Mem Cognit 24:504-510.

Dudley SD (1982) Responsiveness to estradiol in central nervous system of aging female rats. Neurosci Biobehav Rev 6:39-45.

Espeland MA, Marcovina SM, Miller V, Wood PD, Wasilauskas C, Sherwin R, Schrott H, Bush TL (1998) Effect of postmenopausal hormone therapy on lipoprotein ${ }_{\mathrm{a}}$ concentration. PEPI investigators. Postmenopausal estrogen/progestin interventions. Circulation 97:979-986.

Finch CE, Felicio LS, Mobbs CV, Nelson JF (1984) Ovarian and steroidal influences on neuroendocrine aging processes in female rodents. Endocr Rev 5:467-497.

Fischer W, Chen KS, Gage FH, Bjorklund A (1991) Progressive decline in spatial learning and integrity of forebrain cholinergic neurons in rats during aging. Neurobiol Aging 13:9-23.

Frick KM, Baxter MG, Markowska AL, Olton DS, Price DL (1995) Age-related spatial reference and working memory deficits assessed in the water maze. Neurobiol Aging 16:149-160.

Gage FH, Dunnett SB, Bjorklund A (1989) Age-related impairments in spatial memory are independent of those in sensorimotor skills. Neurobiol Aging 10:347-352.

Gallagher M, Burwell RD (1989) Relationship of age-related decline across several behavioral domains. Neurobiol Aging 10:691-708.

Gallagher M, Pelleymounter M-A (1988) An age-related spatial learning deficit: choline uptake distinguishes "impaired" and "unimpaired" rats. Neurobiol Aging 9:363-369.

Garcia-Segura LM, Chowen JA, Parducz A, Naftolin F (1994) Gonadal hormones as promoters of structural synaptic plasticity: cellular mechanisms. Prog Neurobiol 44:279-307.

Gaulin SJ, FitzGerald RW, Wartell MS (1990) Sex differences in spatial ability and activity in two vole species (Microtus ochrogaster and $M$. pennsylvanicus). J Comp Psychol 104:88-93.

Gazzaley AH, Weiland NG, McEwen BS, Morrison JH (1996) Differential regulation of NMDAR1 and mRNA and protein by estradiol in the rat hippocampus. J Neurosci 16:6830-6838.

Geinisman Y, de Toledo-Morrell L, Morrell F (1986) Aged rats need a preserved complement of perforated axospinous synapses per hippocampal neuron to maintain good spatial memory. Brain Res 398:266-275.

Gibbs RB (1996) Expression of estrogen receptor-like immunoreactivity by different subgroups of basal forebrain cholinergic neurons in gonadectomized male and female rats. Brain Res 720:61-68.

Gibbs RB, Pfaff DW (1992) Effects of estrogen and fimbria/fornix transection on p75NGFR and ChAT expression in the medial septum and diagonal band of Broca. Exp Neurol 116:23-39.

Gibbs RB, Wu D, Hersh LB, Pfaff DW (1994) Effects of estrogen replacement on the relative levels of choline acetyltransferase, trkA, and nerve growth factor messenger RNAs in the basal forebrain and hippocampal formation of adult rats. Exp Neurol 129:70-80.

Gould E, Woolley CS, Frankfurt M, McEwen BS (1990) Gonadal steroids regulate dendritic spine density in hippocampal pyramidal cells in adulthood. J Neurosci 10:1286-1291.

Grinnell D, Markowska AL (1998) Ovarian steroid deficiency results in delayed memory impairment. Soc Neurosci Abstr 24:1848.

Halpern DF (1986) Sex differences in cognitive abilities. Hillsdale, NJ: Erlbaum.

Ingram DK (1988) Motor performance variability during aging in rodents. Ann NY Acad Sci 515:70-96.

Jarvik LF (1975) Human intelligence: sex differences. Acta Genet Med Gemellol (Rome) 24:189-211.

Juraska JM, Henderson C, Muller J (1984) Differential rearing experience, gender, and radial maze performance. Dev Psychol 17:209-215.

Kadar T, Silbermann M, Brandeis R, Levy A (1990) Age-related structural changes in the rat hippocampus: correlation with working memory deficiency. Brain Res 512:113-120.

Kampen DL, Sherwin BB (1996) Estradiol is related to visual memory in healthy young men. Behav Neurosci 110:613-617.

Kimura D, Hampson E (1994) Cognitive pattern in men and women is influenced by fluctuations in sex hormones. Curr Dir Psychol Sci 3:57-61.

Krasnoff A, Weston LM (1976) Puberal status and sex differences: activity and maze behavior in rats. Dev Psychobiol 9:261-269.

LeFevre J, McClintock MK (1988) Reproductive senescence in female rats: a longitudinal study of individual differences in estrous cycles and behavior. Biol Reprod 38:780-789.

LeFevre J, McClintock MK (1991) Isolation accelerates reproductive 
senescence and alters its predictors in female rats. Horm Behav 25:258-272.

Lindner MD (1997) Reliability, distribution, and validity of age-related cognitive deficits in the Morris water maze. Neurobiol Learn Mem 68:203-220.

Linn MC, Petersen AC (1985) Emergence and characterization of sex differences in spatial ability: a meta-analysis. Child Dev 56:1479-1498.

Luine VN (1997) Steriod hormone modulation of hippocampal dependent spatial memory. Stress 2:21-36.

Luine V, Rodriguez M (1994) Effects of estradiol on radial arm maze performance of young and aged rats. Behav Neural Biol 62:230-236.

Maren S, De Oca B, Fanselow MS (1994) Sex differences in hippocampal long-term potentiation (LTP) and Pavlovian fear conditioning in rats: positive correlation between LTP and contextual learning. Brain Res 661:25-34.

Markowska AL (1999) Life-long diet restriction failed to retard cognitive aging in Fischer-344 rats. Neurobiol Aging, in press.

Markowska AL, Breckler S (1999) Behavioral biomarkers of aging: an illustration of the multivariate approach for detecting age-related behavioral changes. J Gerontol, in press.

Markowska AL, Stone WS, Ingram DK, Reynolds J, Gold PE, Conti LH, Pontecorvo MJ, Wenk GL, Olton DS (1989) Individual differences in aging: behavioral and neurobiological correlates. Neurobiol Aging 10:31-43.

Markowska AL, Long JM, Johnson CT, Olton DS (1993) Variableinterval probe test as a tool for repeated measurements of spatial memory in the water maze. Behav Neurosci 107:627-632.

Markowska AL, Koliatsos VE, Breckler SJ, Price DL, Olton DS (1994) Human nerve growth factor improves spatial memory in aged but not in young rats. J Neurosci 14:4815-4824.

Markowska AL, Price D, Koliatsos VE (1996) Selective effects of nerve growth factor on spatial recent memory as assessed by a delayed nonmatching-to-position task in the water maze. J Neurosci 16:3541-3548.

Markus EJ, Zecevic M (1997) Sex differences and estrous cycle changes in hippocampus-dependent fear conditioning. Psychobiology 25:246-252.

McEwen BS, Alves SE, Bulloch K, Weiland NG (1997) Ovarian steroids and the brain: implications for cognition and aging. Neurology 48:S8-S15.

Means LW, Kennard KJP (1991) Working memory and the aged rat; deficient two-choice win-stay water-escape acquisition and retention. Physiol Behav 49:301-307.

Means LW, Alexander SR, O'Neal MF (1992) Those cheating rats: male and female rats use odor trails in a water-escape "working memory" task. Behav Neural Biol 58:144-151.

Mishima N, Higashitani F, Teraoka K, Yoshioka R (1986) Sex differences in appetitive learning of mice. Physiol Behav 37:263-268.

Olton DS, Papas BC (1979) Spatial memory and hippocampal function. Neuropsychologia 17:669-682.

Olton DS, Shapiro ML (1992) Mnemonic dissociation: the power of parameters. J Cogn Neurosci 4:200-227.

Olton DS, Markowska AL, Breckler SJ, Wenk GL, Pang K, Koliatsos VE, Price DL (1991) Individual differences in aging: behavioral and neural analyses. Biomed Environ Sci 4:166-172.

Perry EK (1986) The cholinergic hypothesis-ten years on. Br Med Bull 42:63-69.

Price DL, Sisodia SS (1994) Cellular and molecular biology of Alzheimer's disease and animal models. Annu Med Rev 45:435-446.

Rapp PR, Kansky MT, Roberts JA (1997) Impaired spatial information processing in aged monkeys with preserved recognition memory. NeuroReport 8:1923-1928.

Roberts JA, Gilard KVK, Lasley B, Rapp PR (1997) Reproductive senescence predicts cognitive decline in aged female monkeys. NeuroReport 8:2047-2051.

Roof RL (1993) Neonatal exogenous testosterone modifies sex difference in radial arm and Morris water maze performance in prepubescent and adult rats. Behav Brain Res 53:1-10.

Sherwin BB (1994) Estrogenic effects on memory in women. Ann NY Acad Sci 743:213-230.

Sherwin BB (1997) Estrogen effects on cognition in menopausal women. Neurology 48:S21-S26.

Sherwin BB (1998a) Cognitive assessment for postmenopausal women and general assessment of their mental health. Psychopharmacol Bull 34:323-326.

Sherwin BB (1998b) Estrogen and cognitive functioning in women. Proc Soc Exp Biol Med 217:17-22.

Sherwin BB, Tulandi T (1996) "Add-back" estrogen reverses cognitive deficits induced by a gonadotropin-releasing hormone agonist in women with leiomyomata uteri [see comments]. J Clin Endocrinol Metab 81:2545-2549.

Simpkins JW, Singh M, Bishop J (1994) The potential role of estrogen replacement therapy in the treatment of the cognitive decline and neurodegeneration associated with Alzheimer's disease. Neurobiol Aging 15:S195-S197.

Singh M, Meyer EM, Millard WJ, Simpkins JW (1994) Ovarian steroid deprivation results in a reversible learning impairment and compromised cholinergic function in female Sprague Dawley rats. Brain Res 644:305-312.

Terry RD, Katzman R (1983) Senile dementia of the Alzheimer type. Ann Neurol 14:497-506.

Toran-Allerand CD (1996) Mechanisms of estrogen action during neural development: mediation by interactions with the neurotrophins and their receptors? J Steroid Biochem Mol Biol 56:169-178.

van der Staay FJ, de Jonge M (1993) Effects of age on water escape behavior and on repeated acquisition in rats. Behav Neural Biol 60:33-41.

van Haaren F, Wouters M, van de Poll NE (1987) Absence of behavioral differences between male and female rats in different radial maze procedures. Physiol Behav 39:409-412.

Wade SE, Maier SF (1986) Effects of individual housing and stressor exposure upon the acquisition of water maze escape. Learn Motiv 17:287-310.

Warren SG, Juraska JM (1997) Spatial and nonspatial learning across the rat estrous cycle. Behav Neurosci 111:259-266.

Williams CL, Meck WH (1991) The organizational effects of gonadal steroids on sexually dimorphic spatial ability. Psychoneuroendocrinology $16: 155-176$.

Williams CL, Barnett AM, Meck WH (1990) Organizational effects of early gonadal secretions on sexual differentiation in spatial memory. Behav Neurosci 104:84-97.

Woolley CS, McEwen BS (1993) Roles of estradiol and progesterone in regulation of hippocampal dendritic spine density during the estrous cycle in the rat. J Comp Neurol 336:293-306.

Woolley CS, Gould E, Frankfurt M, McEwen BS (1990) Naturally occurring fluctuation in dendritic spine density on adult hippocampal pyramidal neurons. J Neurosci 10:4035-4039.

Zola-Morgan S, Squire LR, Amaral DG (1986) Human amnesia and the medial temporal region: enduring memory impairment after a bilateral lesion limited to field CA1 of the hippocampus. J Neurosci 6:2950-2967. 